\title{
El paciente como "texto" según Ricoeur: implicaciones en bioética
}

Carlos Alberto Rosas Jiménez

\section{Resumen}

Paul Ricoeur sostiene que la narración es vida vivida. Por lo tanto, la experiencia humana posee una dimensión narrativa, es decir, tiene una estructura narrativa y todo esfuerzo que quiera dar cuenta de lo humano tendrá que contar con lo narrativo. Por esta razón, la teoría del texto se convierte para Ricoeur en un modelo general para el estudio de la acción humana, pues esta es concebida como una obra abierta a cualquiera que pueda leer. Teniendo en cuenta este marco general de reflexión, hemos profundizado en la noción del paciente como "texto", y describimos su riqueza para la reflexión de la bióetica y el actuar médico, rescatando el valor de la escucha, la prudencia, la responsabilidad y redescubriendo un lugar para el principio de autonomía y la casuística.

Palabra-clave: Bioética. Pacientes. Autonomía personal. Narración. Ricoeur.

\section{Resumo}

\section{O paciente como "texto" segundo Ricoeur: implicações em bioética}

Paul Ricoeur sustenta que a narração é vida vivida. Portanto, a experiência humana possui uma dimensão narrativa, ou seja, tem uma estrutura narrativa e todo esforço que queira dar conta do humano terá que considerar a narrativa. Por esta razão a teoria do texto se converte para Ricoeur em modelo geral para o estudo da ação humana, pois esta é concebida como uma obra aberta a qualquer um que a possa ler. Tendo em conta este marco geral de reflexão aprofundamos a noção de paciente como "texto" e descrevemos sua riqueza para a reflexão bioética e a atuação do médico, resgatando o valor da escuta, da prudência da responsabilidade e redescobrindo um lugar para o princípio da autonomia e para a casuística.

Palavras-chave: Bioética. Pacientes. Autonomia pessoal. Narração. Ricoeur.

\section{Abstract \\ The patient as "text" according to Ricoeur: bioethic implications}

Paul Ricoeur argues that narration is lived life. Therefore, human experience has a narrative dimension, ie, it has a narrative structure and every effort you want to make for the human need to consider the narrative. For this reason, the text theory is converted to Ricoeur in a general model for the study of human action, since this is conceived as an open work to anyone who can read it. Given this general framework for discussion, we have deepened the notion of the patient as "text", and described their richness for reflection of bioethics and medical act, rescuing the value of listening, prudence, responsibility and rediscovering a place for the principle of autonomy and casuistry.

Key words: Bioethics. Patients. Personal Autonomy. Narration. Ricoeur.

Mestre rosasjcarlos@gmail.com - Universidad de Los Andes, Bogotá/Colombia y Universidad Pontificia Bolivariana, Medellín, Colombia.

\section{Correspondencia}

Carrera 2 Oeste \# 12-31, Cali/Valle del Cauca, Colombia.

Declara não haver conflito de interesse. 
Ricoeur es uno de los grandes representantes de la hermenéutica y es también, aunque esto todavía no ha sido suficientemente subrayado, uno de los grandes teóricos de la ética actual; su filosofía es ética, es reflexión sobre la vida moral, de principio a fin, y es también hermenéutica, una hermenéutica que nace de las insuficiencias de la fenomenología, $o$ de cierta forma de entenderla ${ }^{1}$. El pensamiento Ricoeuriano, dice Alzate ${ }^{2}$, se presenta como una filosofía hermenéutica que lleva la intención de comprender el ser a partir de las acciones expresadas en su existencia, intentando recuperar a la vez, el valor óntico de la persona en su actitud propiamente existencial.

Ricoeur parte de una fenomenología que termina siendo cualificada por la hermenéutica, a diferencia de lo que sucede por ejemplo con Gadamer, quien proponía una hermenéutica fenomenológica ${ }^{3}$. Ricoeur, dice Grondin ${ }^{4}$, hace ver de este modo que, si una hermenéutica sin ética está vacía, una ética sin hermenéutica es ciega. La tarea esencial de la hermenéutica, continúa Grondin, será entonces doble: reconstruir la dinámica interna del texto y restituir la capacidad de la obra de proyectarse al exterior mediante la representación de un mundo habitable ${ }^{5}$.

Uno de los grandes aportes de Ricoeur y el paradigma hermenéutico, como nos dice Moratalla ${ }^{6}$ es haber puesto de manifiesto el carácter narrativo de la experiencia humana, pues las narraciones forman parte de nuestra vida, somos narradores de nosotros mismos; la narración es una forma de producir sentido, de crear imágenes, de establecer síntesis, y allí donde hay sentido - que puede ser múltiple - puede haber ambigüedad, y, por tanto, hay hermenéutica. Ricoeur mismo dice que la narración es vida vivida ${ }^{7}$; por lo tanto, si la experiencia humana es narrativa, tiene estructura narrativa, la racionalidad que dé cuenta de lo humano tendrá que contar con lo narrativo ${ }^{6}$.

Esta teoría del texto se convierte finalmente para Ricoeur, como nos señala Villaroel ${ }^{8}$, en un modelo general para el estudio de la acción humana en cuanto acción significativa, porque esta es concebida como una obra abierta, abierta a cualquiera que pueda leer, y por lo mismo, siempre dotada de un significado en suspenso y resistiendo a cualquier pretensión de encapsulamiento unívoco.

Ricoeur ha delimitado la tensión ética fundamental al decir que se caracteriza por la intencionalidad de la vida buena con y para otro en instituciones justas ${ }^{3} \mathrm{y}$ en sí mismo como otro encontramos una ética propiamente dicha ${ }^{6}$. Todo el fenómeno hermenéutico de Ricoeur cabe también para la Bio- ética ${ }^{9}$, dice Alzate, y como no es ajena a sus planteamientos hermenéuticos, no solo podemos hablar, sino que debemos de hablar, de una bioética hermenéutica; "Ia bioética será hermenéutica - bioética hermenéutica -, o no será" agrega Moratalla ${ }^{10}$.

Con el horizonte que se nos abre al considerar el planteamiento de Ricoeur, queremos acentuar en este trabajo la noción del paciente como texto, pues descubrimos que bajo una bioética hermenéutica se puede lograr tener una mayor comprensión de cada paciente concreto, poner a la persona humana en el centro, no sólo de la reflexión bioética, sino del quehacer médico. Para ello, haremos un breve recorrido sobre el contexto actual de la bioética, luego una consideración del paciente como texto y finalmente las implicaciones que tiene esta noción en la bioética.

\section{La bioética en contexto}

En 1970, V. R. Potter, oncólogo de origen holandés, acuñó la palabra bioética entendida como una ética de la vida que comprendiera no solo los actos del hombre sobre la vida humana, sino también aquella animal y medioambiental ${ }^{11}$. Es innegable que la bioética ha tenido un amplísimo desarrollo desde el momento en que se constituyó como ciencia; sin embargo, esto no necesariamente ha sido positivo a todo nivel. El problema, según Juan María de Velasco ${ }^{12}$, está en que la profusión de ideas y teorías no solo contribuye al enriquecimiento ético, sino que también puede conducir a la confusión y a la falta de criterios para priorizar un sistema moral sobre otro, introduciendo incertidumbre en la toma de decisiones, con el riesgo de generar una bioética de procedimientos sin valores para defender, y vacía.

Ya para el año 2000 se hablaba del modelo biomédico reduccionista, predominante en la comprensión del hecho de la salud, que por su profunda inspiración cartesiana, ha conminado a los médicos a centrarse en esta supuesta máquina del cuerpo y a olvidar los aspectos psicológicos y socioambientales de la enfermedad ${ }^{8}$. De aquí se desprende, como dice Villaroel ${ }^{8}$, la necesidad de reformular un pensamiento que contribuya a desvincular la tarea médica del perfil manipulador que le confiere su exclusiva reducción a práctica mecánica correctora de disfunciones orgánicas específicas. Urge, por tanto, una visión integral de la persona humana, que comprenda las dimensiones biológica, psicológica e incluso espiritual.

A pesar de esta imperante necesidad, el cientificismo médico ha sumido en el olvido, prácticamente, al "arte de curar", que es un aspecto esencial de 
la medicina. No es el objeto de este estudio hacer una descripción exhaustiva de la ética médica en la sociedad actual, sino tomar conciencia de los descalabros éticos, las desviaciones de la bioética y las insuficiencias de los trabajadores de la salud que no contribuyen a construir una cultura de vida, opuesta a una cultura de muerte que deja de lado y olvida rostros concretos de personas, entre las cuales se encuentran algunas que sufren, o ni siquiera pueden expresar su voz y voto.

Como respuesta a esta situación, se ha dado un acelerado crecimiento de la reflexión bioética que ha bebido de varias fuentes del pensamiento filosófico desarrollado a lo largo de la historia. Recientemente se han hecho varios aportes en la línea de la bioética personalista, la cual busca que la reflexión no sólo tenga en cuenta a la persona, sino que emplee este concepto como clave arquitectónica de su antropología ${ }^{13}$.

El personalismo presenta novedades importantes sobre la mirada a la persona humana, tales como ${ }^{13}$ : el hombre como un sujeto individual irrepetible, un quién; la estructura tridimensional de la persona, cuerpo, alma y espíritu; el carácter autónomo, originario y estructural de la afectividad; las relaciones interpersonales; la primacía de la libertad y el amor; la corporeidad, que contempla la sexualidad, entendiendo al hombre como varón y mujer; y otros rasgos como el carácter narrativo de la persona, entre otros. En este último punto encaja la propuesta de la bioética hermenéutica de Ricoeur.

Según Moratalla ${ }^{6}$, existe la necesidad de que la bioética se atreva a dar el salto a lo que podríamos calificar de paradigma hermenéutico. La bioética del futuro necesita atender a lo que la visión hermenéutica puede aportar, y ya no sólo para ser más completa y no dejar fuera ninguna tradición, sino para responder con justicia, responsablemente, a la complejidad de la vida y por consiguiente de la muerte ${ }^{6}$. Urge entonces la necesidad de configurar un estatuto epistemológico de la Bioética, dice Alzate $^{2}$, desde los aportes que ofrece la hermenéutica ricoeuriana, porque la fundamentación filosófica del pensador francés enfatiza una ética solidaria, del compromiso, de la fidelidad a la promesa, de la identidad de una persona sabia, bien informada, que sabe tomar decisiones éticas y del amor en las relaciones de alteridad.

Actualmente seguimos siendo testigos de los atentados y maltratos a la vida humana en hospitales, albergues, orfanatos y en centros de investigación. Eso es, precisamente, como dice Villaroel ${ }^{8}$, lo que nos mueve a sostener que resulta factible con- cebir la bioética en relación con una perspectiva de naturaleza hermenéutica, avanzando en la dirección de situar como eje central de la argumentación respectiva, la noción de interpretación.

Alzate ${ }^{2}$ menciona que una práctica bioética es la que puede ser interpretada, es decir, los símbolos, las formas de actuar del médico, del paciente, e incluso la contemplación de la propia naturaleza y la crisis ecosistémica. Sin embargo, el elemento narrativo de la bioética hermenéutica apunta también a la necesidad de interpretación del paciente; busca aproximarse al paciente como un texto que necesita ser leído en su totalidad e integralidad para poder ser plenamente comprendido.

\section{El paciente como texto}

La complejidad de la persona humana puede de alguna manera encontrar un paralelo con la noción de texto, pues todo lo que es susceptible de ser comprendido puede ser considerado texto: no solamente los escritos mismos, claro está, sino también la acción humana y la historia, tanto individual como colectiva, que solo son inteligibles en la medida en que puedan leerse como textos ${ }^{14}$. Entiéndase bien que la noción de "texto" en ningún momento lleva a una cosificación de la persona humana ni rebaja su dignidad; más bien, enuncia una disposición peculiar del pensar en la que se busca transitar desde el sistema acabado y definitivo del reduccionismo cientificista que toca al ser del hombre como objeto de un saber positivo o exacto, al borde diferencial hermenéutico - basado en el pensar interpretativo donde lo humano es atestiguado desde su intrínseca condición problemática, inconclusa, conjetural e imprevisible, reticente a cualquier cierre conceptual ${ }^{8}$.

Si la bioética tiene que centrarse en la persona humana y no perder su mirada sobre ella; tiene que aprender a ver al paciente como un libro abierto que le ofrece múltiples páginas que tienen que ser leídas para dar un dictamen sobre su condición, sobre su salud. Es por eso que el verdadero arte de curar debería entender al paciente en su condición de texto, es decir, de realidad abierta y multívoca ${ }^{8}$. En la persona humana, todo lo que concierne a su existencia tiene significado, su enfermedad por ejemplo, en cuanto experiencia humana, es siempre un hecho lleno de significado ${ }^{15}$. Lo anterior implica que la bioética ha entendido de cierta manera al paciente como un texto; de hecho, según Moratalla, la ética médica ha contado a lo largo de su historia con estas importantes intuiciones, ya que la vida humana no 
es sólo biológica sino biográfica, y que la enfermedad se sufre y padece biográficamente ${ }^{16}$. Por eso es objeto de apropiación y de interpretación, contribuyendo a crear una vivencia original e irrepetible ${ }^{15}$.

En el ámbito de la salud, la ciencia médica nos arroja datos, de gran utilidad, no cabe duda, pero al fin y al cabo, datos. Allí está siempre presente la realidad de la persona que sufre, con una historia particular, única e irrepetible. Esta realidad biográfica, histórica pero al mismo tiempo actual del paciente, es de donde se obtienen grandes luces sobre su condición de salud particular y donde se esbozan las posibles soluciones para curar su enfermedad o alcanzar su mejoría. Pasamos, como diría Alzate ${ }^{2}$, de la razón abstracta a la razón narrativa. Sin duda el médico posee un aval en su saber técnico, pero el único órgano desvelador de que dispone como lector para acceder a ese "texto" ${ }^{16}$, es su propia realidad personal; por lo cual no puede sino admitir que frente a la situación de su contraparte, el enfermo, no existe una interpretación única, en efecto la interpretación de sus circunstancias es siempre múltiple.

Las historias clínicas son la mejor prueba de la presencia de la narrativa en la medicina, como esfuerzo por comprender al paciente y encontrar una solución a sus problemas. La doctora Imízcoz ${ }^{17}$ señala que los escritos científicos abarcan solamente la descripción y la explicación de una enfermedad, mientras que la historia clínica abarca la realidad de la enfermedad, pues esta pasa a ser algo concreto, encarnado en una persona. No obstante, la enfermedad nunca es algo puntual, es un proceso que tiene una duración y requiere ser contado, por eso, en las historias clínicas se buscan antecedentes familiares, síntomas anteriores, hechos que puedan arrojar luz sobre el estado actual del paciente ${ }^{17}$.

La consideración de la historia clínica, vista desde una perspectiva narrativa, más que funcional, permite que el paciente se vea y sea visto desde una perspectiva diferente. Si las historias clínicas pueden resultar complejas, es porque la realidad del paciente mismo es mucho más compleja. El paciente es un texto que debe ser leído de principio a fin, con la mayor atención, relacionando su pasado con su presente y vislumbrando su futuro, pues eso ayuda al lector a comprenderlo e interpretarlo mejor.

Esta noción del paciente como "texto" tiene implicaciones directas en la bioética, que hemos querido esbozar de la siguiente manera: la escucha al paciente, la prudencia, la responsabilidad, y una mejor comprensión de la autonomía del paciente y de la casuística en el juicio bioético.

\section{El "texto" requiere ser escuchado}

El hecho de que el paciente sea visto como un texto, nos dice Villaroel ${ }^{8}$, es sinónimo de que en su ser de enfermo pueden emerger palabras que deben ser extraídas del silencio, palabras cuyo decir es siempre múltiple y están a la espera de nuevas interpretaciones que decidan su significación, palabras que, además, estarán abiertas a los muchos que puedan leerlas, a todas las instancias sociales que pueden proveer, en mayor o menor medida, salud. De esta manera, el actuar médico reconoce la compleja pluridimensionalidad de lo humano, que no podrá ser comprendido ni bien explicado si no contempla su vastedad y pluralidad ${ }^{8}$.

Por otro lado, si el paciente es entendido como texto, el futuro médico debe recibir un buen entrenamiento para aprender a desarrollar su capacidad de escucha de lo que el "texto" quiere decir. Su formación tiene que incluir una dimensión humanística, en concreto cultivada mediante la lectura de textos, que tengan que ver con temas expresamente médicos, pero en general, que busque adentrarse en la literatura. De este modo, los médicos, como suele pasarle a muchos, no pensarán que lo único que tienen que dominar es el conocimiento científico de su profesión. El médico se dará cuenta, entonces, de que no solo existen enfermedades, sino que existen principalmente enfermos, personas concretas que padecen alguna enfermedad.

Russo dice que este ejercicio de formación en la dinámica narrativa es indispensable para crecer en humanidad (...) y puede contribuir a hacer más profunda la capacidad de comprensión del médico en relación con sí mismo y los demás, y también más aguda su sensibilidad (...) podrá ayudar a percibir la complejidad que también la vivencia de un hombre físicamente sano presenta, y a darse cuenta de que el dolor humano representa una realidad mucho más amplia y difícil de explorar que el mero sufrimiento físico ${ }^{18}$. Este ejercicio formativo tiene consecuencias directas en el juicio y la reflexión bioética pues permitirá que se formen generaciones de médicos que además de estar más atentas a los pacientes por medio de lo que dice la historia clínica, puedan ser más sensibles a la historia de la enfermedad del paciente con un rostro concreto y que afecta la realidad de su dolor y sufrimiento.

La capacidad de escucha desarrollada por el médico crece a la par con la autoescucha del mismo texto, que al ser narrado se comprende mejor a sí mismo, pues la narración es un componente fundamental en la expresión del síntoma y la comprensión por parte del paciente ${ }^{6}$. Al respecto Virraroel 
advierte: La hermenéutica es diálogo ${ }^{19}$ y la repercusión en la bioética es que ese diálogo debe ejercerse efectivamente más allá de posiciones puramente descriptivas que soslayen el problema de la relación entre observador y observado ${ }^{8}$.

Es necesario dejar claro que aunque está muy presente el diálogo y la consideración holística de las condiciones del paciente, eso no puede suponer una negociación de los principios bioéticos, entre ellos la dignidad humana; la vida humana tiene que tenerse siempre como un valor absoluto.

\section{Aproximación al "texto" con prudencia}

Según Moratalla, con Ricouer la bioética adquiere consistencia ética gracias al nivel de la prudencia, la bioética es, y no puede no serlo, cuestión de juicio prudencial, constituyéndose en el primer nivel de la práctica médica ${ }^{6}$. Ricoeur enumera tres preceptos en este nivel prudencial: el primer precepto hace referencia a la singularidad de cada persona en su carácter insustituible. El segundo, versa sobre la indivisibilidad, es decir, la necesidad de tratar a la persona como un todo y no de una forma fragmentada, ya sea al considerar de una forma aislada cada parte del cuerpo, motivado sin duda por la especialización de los saberes médicos, o al desvincular los elementos biológicos, psicológicos y socioculturales. El tercero, es el de la estima de sí, que se refiere a cierto señorío de sí mismo ${ }^{6}$.

De acuerdo con Moratalla ${ }^{6}$ en el nivel prudencial la facultad de juzgar se aplica a situaciones singulares en que un paciente individual está situado en una relación interpersonal con un médico individual, y el tipo de saber no es otro que el propio de la sabiduría práctica cercana al ejercicio de la profesión, con un carácter más o menos intuitivo. Hasta el momento hemos podido observar que en el fondo del planteamiento hermenéutico de Ricoeur existe un especial cuidado por el texto. Esta es pues, una de las razones por las cuales la categoría de texto puede ser aplicada al paciente. Antes que nada debe ser escuchado y ahora, tratado con prudencia, que incluye considerar su carácter insustituible, su indivisibilidad y el señorío de sí mismo con el que exige ser tratado. Es por ello que Ricoeur ha llamado al pacto de cuidados, el corazón de la bioética ${ }^{6}$.

\section{El "texto" reclama responsabilidad}

La dimensión del cuidado que se deriva de la prudencia con que se trata el texto, tiene su concreción en la responsabilidad. No existe verdadero cuidado sin responsabilidad. Es por eso que aunque la bioética de Ricoeur puede ser considerada en una doble perspectiva: perspectiva clínica o terapéutica y perspectiva orientada a la investigación, se debe centrar la atención en la perspectiva terapéutica, donde la bioética será básicamente aquella disciplina que se las tiene que ver con el curar y cuidar ${ }^{6}$. No hay conflicto en Ricoeur, dice Moratalla ${ }^{6}$, entre una hermenéutica de los textos y una ética del cuidado del otro.

Partimos de aquello que dice Ricoeur: hacer de otro mi semejante, tal es la pretensión de la ética en lo que concierne a la relación entre la estima de sí y la solicitud ${ }^{20}$. La responsabilidad, de quien verdaderamente se hace cargo de alguien, significa considerar al otro como semejante. Sencillamente, no puedo no responderle al otro, como dicen Belli y Quadrelli: Debo cuidar del Otro porque está allí, frente a mí, pidiéndome ayuda y no tengo otra opción que responder a su pedido para constituirme en mi propia humanidad (...) Mi responsabilidad hacia aquel que sufre es un permanente llamado a dar y a servir ${ }^{21}$.

La hermenéutica que se orienta éticamente, como la de Ricoeur, no tendrá un objetivo distinto a la toma de decisiones responsables y la ética hermenéutica que de allí se deriva, en cualquiera de sus variaciones, no podrá dejar de ser siempre una ética de la responsabilidad ${ }^{6}$. El médico y los trabajadores de la salud se harán realmente responsables del paciente, entendido como texto, si ellos también descubren para sí mismos esa realidad de texto, abiertos a ser leídos y comprendidos.

\section{La pasividad y el principio de autonomía del "texto"}

Como hemos visto, la lectura e interpretación del texto es un proceso dinámico, en el que intervienen lector y texto, que entran en permanente diálogo; sin embargo, el texto posee un grado de pasividad en el sentido de que espera ser leído, escuchado para ser comprendido. Esto está en directa relación con la realidad del paciente pues el ser humano no es solamente aquel capaz, aquel que puede; también es el incapaz, el que no puede, y todos somos esa mezcla de capacidad e incapacidad, todos somos hechos antes de ponernos a hacer y esto es lo que nos hacer ser, en un sentido, pasivos antes que activos ${ }^{22}$.

$Y$ es que el reconocimiento de la pasividad, la contingencia, los grados de no poder, el sufrimiento, la finitud de nuestra vida, la debilidad o nuestra vulnerabilidad intrínseca, nos mueven a considerar la realidad de la persona humana como un entramado de autonomía y vulnerabilidad, que tiene que ser considerada así si quiere decir algo con sentido ${ }^{23}$. Como hemos anotado en otro estudio: toda la realidad del 
ser humano, incluso en momentos de mayor dolor y angustia por la presencia intensa del mal y del sufrimiento, se llena de sentido cuando descubre que es frágil y débil y que por tanto, tratar de alejar la experiencia del dolor y del sufrimiento es algo imposible ${ }^{24}$.

Esta pasividad no le roba todo lo dinámico que puede llegar a ser el "texto", pero en la reflexión bioética, la consideración de esa pasividad se convierte en un filtro del principio de autonomía, pues no podemos hacer todo lo que queremos siempre; por ejemplo, una pareja de esposos es libre de querer tener hijos, pero su autonomía no puede pasar por encima de la consideración de que para tenerlos tiene que recurrir a medios de reproducción asistida que incluyen la muerte de varios embriones en el proceso ${ }^{24}$.

\section{El "texto" y la casuística}

Uno de los grandes cuestionamientos que se le ha hecho a la bioética es la casuística excesiva ${ }^{25,26}$. Feito ${ }^{27}$ describe algunas de las críticas de la siguiente manera: en primer lugar por poder convertirse una mera ilustración decorativa que no aporta nada nuevo a la reflexión; en segundo lugar, por la dificultad que conlleva el análisis profundo de la situación, cuando se buscan diversas interpretaciones en dimensión narrativa; en tercer lugar, por adoptar una perspectiva casuística que puede confundir a la hora de establecer patrones universales sobre lo correcto y lo bueno.

Frente a este obstáculo, sale a su paso el modelo hermenéutico-narrativo, pues evita no solo el casuismo, sino también el deductivismo principialista; aboga no tanto por partir de los casos sino más bien por las narraciones, es decir, los casos en contexto ${ }^{6}$. Para superar la casuística ayuda mucho en la solución de los casos presentarse desde más de una perspectiva, pues tener la posibilidad de ver otros puntos de vista contribuye a una mejor y más completa comprensión de la situación ${ }^{27}$.

Es necesario, sin lugar a dudas, atender al caso, pero tampoco podemos caer en hacer que la sabiduría práctica sea transformar en regla la excepción a la regla ${ }^{28}$. El paciente es un ser humano, antes que un caso a analizar, que posee una dignidad y valores propios que son absolutos por su calidad de persona humana.

\section{Consideraciones finales}

La noción del paciente como "texto" que se deriva de la bioética hermenéutica de Ricoeur se presenta como una propuesta a los periódicos atentados a la persona humana, que reclaman una postura ética con tal fuerza que pueda hacer frente a posturas filosóficas o a acciones $u$ omisiones que no terminan de salir en defensa de la vida humana desde su concepción hasta su fin natural. La consideración de esta noción tiene varias implicaciones en bioética.

En primer lugar, el "texto" está a la espera de ser leído, de ser comprendido. Aquí no vale la lectura de los resúmenes del texto; quien se aproxima al texto con una actitud mediocre y de poco interés por él, no puede sacar conclusiones, no sabrá dar cuenta del texto, nunca va a terminar de comprender lo que el texto realmente quería decir. Por esta razón, es necesaria la escucha del "texto". Esta es la mayor implicación en bioética de la noción del paciente como texto, pues con mucha más razón el paciente tendrá que ser extensamente escuchado.

En segundo lugar, nos encontramos con la prudencia. Se requiere llegar a ese nivel prudencial del que habla Ricoeur para ser cuidadoso con el "texto", tanto así que a este nivel prudencial lo ha llamado el corazón de la bioética. A través de la prudencia el médico y el trabajador en salud logran descubrir la grandeza y complejidad que contiene el "texto", de los cuidados que requiere y por tanto, a obrar con prudencia. Sin embargo, no se puede obrar éticamente sin responsabilidad. Hoy en día un paciente suele estar a cargo de alguien, más como un cliente, como una "camilla" más que atender, o como un caso más que resolver, que como un "texto" que espera ser leído. Comprende bien a su paciente quien se ha hecho cargo de él, quien ha "leído el texto completo", quien se ha hecho responsable de él.

Por otro lado, si bien el "texto" posee un carácter de individualidad e independencia no puede desentenderse de su fragilidad, por lo que se debe partir de esta realidad si quiere decir algo con sentido. El texto espera ser leído, su autonomía no lo lleva a decidir hacer lo que sea, como si fuera todopoderoso, invencible y plenipotenciario; la verdadera autonomía considera la pasividad del "texto". Ningún paciente puede perder su autonomía, pero su realidad está ligada a la contingencia de la persona humana, que tiene en cuenta la lectura que hace el médico, los familiares y los amigos que dan su parecer.

Finalmente, la noción del paciente como texto permite encontrar un lugar adecuado a la casuística en la reflexión bioética. La bioética hermenéutica analiza cada caso y está abierta a las múltiples interpretaciones, pero considera al paciente como 
una persona humana, que antes que un simple caso a analizar, posee una dignidad y valores propios que son absolutos.

Queremos resaltar que la bioética hermenéutica no hace menos objetivo ni menos científico el quehacer y el juicio bioético. La posibilidad de que existan varias interpretaciones y pluralidad de perspectivas, no hacen de la bioética un "saber de lo incierto", como dice Feito ${ }^{29}$, más bien, pensamos que el valor de la bioética hermenéutica está en su consideración del paciente como texto, como una realidad abierta a ser comprendida, pues de no existir, no tendría sentido tampoco la existencia del lector o de su intérprete, en este caso los médicos y los trabajadores en salud.

Llegados a este punto, podemos lanzar aquí un interrogante entre muchos otros ¿por qué habría entonces un lector de eliminar su texto si su objetivo es leerlo? Análogamente ¿por qué habría entonces un médico de eliminar el "texto" que tiene que leer si ha consagrado su vida a la lectura, análisis e intervención de "textos"? Estas y muchas preguntas comienzan a ser más claras cuando nociones como la de "texto" se aplican en la bioética, a esa persona concreta que sufre y padece algún tipo de dolencia o discapacidad.

\section{Referências}

1. Moratalla TD. Bioética y hermenéutica. La aportación de Paul Ricoeur a la bioética. Veritas. 2007; 2(17). p. 283.

2. Alzate NA. Aportes de la hermenéutica ricoeuriana a la bioética. [dissertação]. Bogotá: Pontificia Universidad Javeriana/Instituto de Bioética; 2011.

3. Grondin J. ¿Qué es la hermenéutica? Barcelona: Herder; 2008.

4. Grondin J. Op. cit. p. 126.

5. Grondin J. Op. cit. p. 117-8.

6. Moratalla TD. Op. cit. 2007:281-312.

7. Ricoeur P. Sí mismo como otro. Mexico: Ediciones Sígueme; 1990. p. 193.

8. Villarroel R. Bioética hermenéutica. Acta Bioethica. 2000; 6: 143-57.

9. Alzate NA. Op. cit. p. 47.

10. Moratalla TD. Op. cit. 2007: 312.

11. Postigo E. Concepto de bioética y corrientes actuales. In: Tomás y Garrido GM, Postigo Solana $H$, coordinadores. Bioética personalista. Madrid: Ediciones Internacionales Universitarias; 2007. p. 17-38.

12. De Velasco JM. La bioética y el principio de la solidaridad. Bilbao: Universidad de Deusto; 2003.

13. Burgos JM. ¿Qué es la bioética personalista? Un análisis de su especificidad y de sus fundamentos teóricos. Cuadernos de Bioética. 2013;80(24):17-30.

14. Grondin J. Op. cit. p. 119.

15. Russo MT. Bioética y literatura: una propuesta para una antropología del sufrimiento. Persona y Bioética. 2006;10(2): 122.

16. Moratalla TD. Consideraciones éticas y bioéticas sobre la tarea médica: Entre "arte de curar" y "saber/poder". Revista Chilena de Neuropsicología. 2010; 5:38-45.

17. Imízcoz T. Contarse y curarse. Reflexiones sobre literatura y enfermedad. In: Anrubia E, editor. La fragilidad de los hombres. Madrid: Fuenlabrada; 2008. p. 103-24.

18. Russo MT. Op. cit. 2006: 128.

19. Villaroel R. Op. cit. p. 155.

20. Ricoeur P. Amor y justicia. Madrid: Caparrós Editores; 2001. p. 108.

21. Belli L, Quadrelli S. La ética como filosofía primera: una fundamentación del cuidado médico desde la ética de la responsabilidad. Cuadernos de Bioética. 2010; 21: 13-20. p. 19.

22. Moratalla TD. Lectura bioética del ser humano: autonomía y vulnerabilidad. Thémata. 2004; 33 : 425.

23. Moratalla TD. Op. cit.; 2004: 423-8.

24. Rosas CA. La comprensión del dolor en la reflexión bioética: una aproximación preliminar. Persona. Revista Iberoamericana de Personalismo Comunitario. 2013; 22: 83-6.

25. Gómez CA. Bioética: más allá de la casuística. Diario el Pulso. 2008; 121 (Octubre).

26. Rosas CA. La solidaridad como un valor bioético. Persona y Bioética. $2011 ; 15(1)$ : 10-5.

27. Feito L. Bioética narrativa. Bulletí del Comitè de Bioètica de Catalunya. 2013; 9: 1-7.

28. Moratalla TD. Op. cit. 2007. p. 293.

29. Feito L. Op. cit. p. 7.

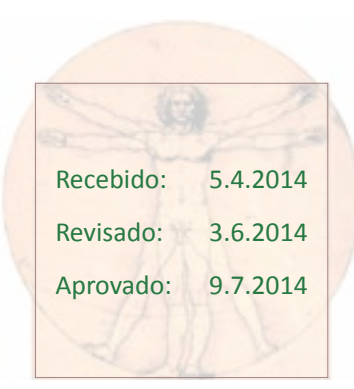

